\title{
PENDEKATAN KONSEP TOD DALAM DESAIN FASILITAS PUSAT TRANSPORTASI PUBLIK DAN RUANG KOMUNAL DI RAWA BUAYA
}

\author{
Filip Julianus Sudjana ${ }^{1)}$, Sidhi Wiguna Teh ${ }^{2)}$ \\ 1)Program Studi S1 Arsitektur, Fakultas Teknik, Universitas Tarumanagara, filipjulianus02@gmail.com \\ 2) Program Studi S1 Arsitektur, Fakultas Teknik, Universitas Tarumanagara, sidhi@ft.untar.ac.id
}

Masuk: 04-07-21, revisi: 15-08-21, diterima untuk diterbitkan: 23-10-2021

\begin{abstract}
Abstrak
Jaringan sirkulasi penduduk adalah hal penting yang menyangkut moda transportasi dan mobilitas penduduk yang dimiliki suatu kota. Bila jaringan ini buruk, akan menyebabkan menurunnya akses bagi pejalan kaki, pemborosan bahan bakar kendaraan bermotor, serta memburuknya tingkat kualitas udara dalam kota. Daerah Rawa Buaya merupakan daerah yang terdapat banyak moda transportasi. Tetapi, moda transportasi ini kurang tertata dengan baik sehingga menciptakan titik kemacetan pada kawasan ini. Konsep Transit Oriented Development (TOD) diciptakan sebagai salah satu solusi pembangunan kota yang sustainable dalam hal transportasi yang berfokus pada sirkulasi dan aksesibilitas. Konsep TOD ini sangatlah cocok untuk diterapkan untuk terminal yang ada di kota Jakarta, yang memiliki kriteria untuk menggunakan terminal berbasis TOD. Kawasan Transit Oriented Development (TOD) ini akan membantu masyarakat dalam kota Jakarta khususnya daerah Rawa Buaya, Jakarta Barat untuk menciptakan moda transportasi yang ramah pejalan kaki dan dapat menghubungkan wilayah-wilayah pada kawasan ini. Metode desain yang digunakan berdasarkan preseden yang sudah ada akan mengambil contoh langsung pengalaman pengguna dari beberapa pusat transportasi yang sudah berhasil. Perancangan desain pusat transportasi ini diharapkan dapat meningkatkan minat masyarakat untuk menggunakan transportasi umum dan membantu mengurangi kemacetan dalam kota.
\end{abstract}

Kata kunci: aksesibilitas; pusat transportasi; transit oriented development; Rawa Buaya

\begin{abstract}
The population circulation network is an important matter regarding the modes of transportation and mobility of the population owned by a city. If this network is bad, it will lead to decreased access for pedestrians, waste of motor vehicle fuel, and worsening of the level of air quality in the city. The Swamp Crocodile area is an area that has many modes of transportation. However, this mode of transportation is not well organized, creating congestion points in this area. The concept of Transit Oriented Development (TOD) was created as a solution for sustainable urban development in terms of transportation that focuses on circulation and accessibility. The TOD concept is very suitable to be applied to terminals in the city of Jakarta, which have criteria for using TOD-based terminals. This Transit Oriented Development (TOD) area will help people in the city of Jakarta, especially the Rawa Buaya area, West Jakarta to create a pedestrian-friendly mode of transportation that can connect areas in this area. The design method used is based on existing precedents and will take direct examples of user experiences from several successful transportation hubs. This design is expected to increase public interest in using public transportation and help reduce congestion in the city.
\end{abstract}

Keywords: accessibility; transportation hub; transit oriented development; Rawa Buaya

\section{PENDAHULUAN}

Latar Belakang

Jakarta merupakan kota metropolitan dengan pertumbuhan penduduk dan ekonomi yang paling pesat karena merupakan ibukota negara Indonesia. Menurut Wikipedia.org (2021), Jakarta memiliki luas sekitar 661,52 km² dengan jumlah penduduk 10,77 juta jiwa tahun 2021. Jumlah ini terus 
bertambah karena tingkat urbanisasi dari desa menuju kota yang terus meningkat. Berdasarkan data, kepadatan penduduk Kota Jakarta Barat memiliki jumlah kepadatan tertinggi dengan jumlah 19993 jiwa per meter ${ }^{2}$ (Badan Pusat Statistik Kota Jakarta, 2019).

Seiring dengan hal tersebut dan sejalan dengan berkembangnya wilayah Jakarta Barat, membuat fasilitas transportasi umum yang ada tidak memadai lagi untuk mewadahi kebutuhan dan harapan penduduk yang terus bertambah. Fasilitas transportasi umum yang terdampak masalah ini salah satunya adalah terminal. Pengguna fasilitas pusat transportasi ini seiring berjalannya waktu bertambah banyak sedangkan fasilitas tidak bertambah luas dan penggunaan kendaraan pribadi terus meningkat (Portal Statistik Sektoral Provinsi DKI Jakarta, 2017). Untuk itu pemerintah kota setempat harus memberlakukan perancangan pusat transportasi dengan konsep Transit Oriented Development (TOD) untuk dapat menyelesaikan permasalahan ini.

Transit oriented development (TOD) adalah konsep pengembangan tata kota yang terintegrasi dengan sistem transportasi untuk menciptakan sebuah kota yang efisien. Konsep TOD memiliki sebuah tujuan untuk memberikan sebuah alternatif dan pemecahan masalah bagi pertumbuhan kota yang cenderung memiliki pola pengembangan yang berorientasi. Konsep ini mengintegrasikan jaringan transit secara regional dan melengkapi strategi pengembangan lingkungan yang telah ada di sekitar simpul transit. Kawasan transit oriented development (TOD) menggabungkan guna lahan residensial, perdagangan, jasa, kantor, ruang terbuka, dan ruang publik sehingga memudahkan masyarakat dan pengguna untuk melakukan perjalanan dengan berjalan kaki, sepeda, maupun moda transportasi umum (Calthorpe, 1993).

Menurut Sung dan Oh dalam Ogra dan Ndebele (2014), TOD adalah sebuah teknik perencanaan yang bertujuan untuk mengurangi pemakaian kendaraan pribadi bermotor dan mendukung konsep pemakaian transportasi umum massal dan kendaraan tidak bermotor. Kawasan TOD ini merupakan kawasan yang memiliki zona fungsi lahan campuran yang dirancang secara teliti dengan aksesibilitas yang nyaman dan aman menuju ke titik transit (Suzuki et al dalam Ogra dan Ndebele, 2014).

Merangkum dari pendapat-pendapat para ahli, hal utama dalam penerapan konsep TOD adalah penggabungan antara moda-moda transportasi publik bersistem transit dengan suatu kawasan yang memiliki zonasi lahan campuran dan kepadatan masyarakat yang memiliki mobilitas tinggi. Penggabungan yang dimaksud berupa aksesibilitas yang tinggi untuk pedestrian, dengan penyediaan jalur pejalan kaki berupa connector yang dapat menghubungkan titik transit menuju sebuah kawasan atau menuju titik transit yang lain.

Penerapan konsep Transit Oriented Development di Indonesia sudah dapat terlihat di Kota Jakarta. Dari beberapa contoh, salah satunya Kawasan TOD Dukuh Atas yang terletak di pusat arteri ibukota (Jalan Sudirman). Berdasarkan kegiatan, Kawasan Dukuh atas merupakan salah satu pusat kegiatan perdagangan dan jasa, perkantoran, niaga, dan pelayanan skala internasional, serta terdapat stasiun terpadu dan titik transit beberapa macam moda transportasi. Sebelum ditetapkan menjadi kawasan TOD, menurut Perda no.6 Tahun 1999, Dukuh Atas termasuk dalam salah satu sistem pusat kegiatan utama yang merupakan pusat niaga terpadu. Pada kawasan tersebut terdapat pengaplikasian sistem angkutan umum massal yang merupakan salah satu strategi pengembatangan tata ruang pemerintah provinsi. Berdasarkan hal tersebut, dapat dilihat bahwa Kawasan TOD Dukuh Atas selaras dengan konsep pengembangan TOD, yaitu kawasan pusat aktivitas dengan fungsi lahan campuran dan terdapat sistem transportasi umum massal di kawasannya.

Pemerintah Provinsi DKI Jakarta berencana untuk membuat Stasiun Rawa Buaya menjadi Terminal Tipe A yang dapat menampung transjakarta, terminal dalam kota, dan stasiun untuk kereta listrik. Rencana ini sudah ada dari tahun 2017 tapi belum direalisasikan. Terdapat juga rencana MRT (Koridor 
Timur-Barat) fase 3 , sehingga sangat meningkatkan potensi untuk diwujudkannya pusat transportasi yang mengaplikasikan konsep kawasan TOD di Rawa Buaya

\section{Rumusan Permasalahan}

- Bagaimana arsitektur dapat mewadahi kebutuhan transportasi umum di kota yang berintegrasi dengan prinsip transit oriented development?

- Program apa yang akan dibuat untuk memfasilitasi kebutuhan moda transportasi umum massal agar pengguna merasa nyaman dan aman?

\section{Tujuan}

- Mewadahi kebutuhan penduduk yang sangat padat akan mobilitas untuk berpergian dari dan ke pusat kota

- Mendukung program pemerintah dalam mewujudkan penduduk yang cenderung memilih transportasi umum daripada kendaraan bermotor pribadi

- Meningkatkan kualitas kenyamanan dalam terminal baik dalam bidang transportasi umum, bidang pedestrian, dan bidang transportasi pribadi

- Menciptakan kawasan terminal yang bersih dan ramah dengan lingkungan dan penduduk.

\section{KAJIAN LITERATUR}

\section{Beyond Ecology Architecture}

Menurut Agustinus Sutanto, Beyond Ecology diartikan sebagai suatu usaha untuk mempelajari suatu kondisi saat ini dari suatu ekosistem yang saat ini sedang terjadi di bumi ini. Melihat ke dalam bagaimana peranan arsitektur dalam menghasilkan suatu karya arsitektur yang indah dan berguna untuk masyarakat. Dalam konteks ini ajakan untuk melampui arsitektur untuk melakukan spekulasi dan spatialitas dari ekosistem yang sedang dirasakan oleh bumi saat ini. Aspek ini ternyata dilihat juga dari kualitas spasial dengan menempatkan posisi kompleksitas dan keunikan dari ekosistem yang ada di sekitarnya.

\section{Pengertian Transit Oriented development Menurut Calthorpe (1993)}

Menurut Calthorpe (1993) Transit oriented Development adalah kawasan dengan zonasi campuran yang berada di dalam jarak rata-rata berjalan kaki sejauh 600 meter dari inti titik transit. Zona campuran TOD merupakan perumahan, ritel, perkantoran, ruang terbuka, dan ruang publik di lingkungan yang dapat dilalui dengan berjalan kaki, membuat nyaman bagi penghuni dan karyawan untuk bepergian dengan angkutan umum, sepeda, berjalan kaki atau mobil.

\section{Menurut Perda Prov DKI no. 1 Tahun 2012}

Menurut perda DKI, tentang RTRW 2030, kawasan TOD merupakan kawasan campuran pemukiman dan komersil dengan aksesibilitas tinggi terhadap angkutan umum massal, dimana stasiun angkutan umum dan terminal angkutan umum sebagai pusat kawasan dengan bangunan berkepadatan tinggi.

Pada inti pokoknya, konsep ini memiliki sebuah tujuan dengan memberikan alternatif pemecahan masalah untuk kota metropolitan yang memiliki pertumbuhan penduduk sangat tinggi. Dengan membuat suatu zona mixed-use yang serasi dalam radius lima hingga lima belas menit berjalan kaki pada kawasan titik transit yang diharapkan dapat memberikan manfaat bagi ruang kota itu sendiri. Seperti, terjadinya pergerakan yang teratur antar hunian, perkantoran, dan fungsi lain dalam kawasan yang dicakup oleh titik TOD. Akumulasi pergerakan yang teratur ini diharapkan membuat penduduk beralih menggunakan transportasi umum massal daripada kendaraan pribadi. 


\section{Prinsip Urban Design Transit Oriented Development}

Menurut TOD Standard 2.1 yang dikeluarkan oleh Institute for Transportation and Development Policy yang bermarkas di New York, Amerika, terdapat delapan point untuk mencapai tujuan konsep TOD, yaitu:

a. Berjalan kaki (Walk) Berjalan kaki adalah moda transportasi yang paling dasar dimiliki oleh manusia. Paling alami, sehat, dan tidak menyebabkan polusi. Berjalan kaki ini dapat menjangkau jarak pendek pada titik transit sehingga menjadi yang paling dasar dalam pergerakan dengan menggunakan kendaraan umum.

b. Bersepeda (Cycle)

c. Bersepeda adalah salah satu pilihan transportasi yang juga menyehatkan dan tidak menyebabkan polusi. Sepeda ini setelah digunakan hanya mengkonsumsi sedikit ruang untuk parkir dan tidak memerlukan sumber daya yang dimiliki perkotaan.

d. Menghubungkan (Connect)

e. Jalur yang tersedia harus menghubungkan pejalan kaki dengan jaringan-jaringan yang padat diantara kawasan kota yang padat.

f. Menghubungkan (Connect)

g. Jalur yang tersedia harus menghubungkan pejalan kaki dengan jaringan-jaringan yang padat diantara kawasan kota yang padat.

h. Pembauran (Mix)

i. Pembaruan fungsi zonasi lahan dalam satu kawasan dapat membuat jalan akses menjadi terus hidup, membuat aktivitas berjalan dan bersepeda menjadi diminati, dan memberikan rasa aman pada lingkungan.

j. Memadatkan (Densify)

k. Untuk dapat menopang pertumbuhan kota dalam pola yang padat dan rapat. Kota harus tumbuh vertikal, bukan horizontal untuk menghindari terjadinya sprawl.

I. Merapatkan (Compact)

$\mathrm{m}$. Prinsip dasar pembangunan kota yang padat adalah tata ruang yang rapat, membuat berbagai kegiatan dan aktivitas saling berdekatan.

n. Beralih (Shift)

o. Ketika kota sudah mewujudkan ketujuh prinsip diatas, kendaraan pribadi sudah hampir tidak dibutuhkan untuk kehidupan sehari-hari. Berjalan kaki, bersepeda, kendaraan umum massal akan menjadi pilihan utama yang nyaman dan aman yang lebih hemat dalam penggunaan ruang kota.

\section{METODE}

Metode perancangan yang digunakan adalah metode 'Preseden' yang merupakan cara yang dilakukan atau dikatakan dapat berfungsi sebagai contoh atau aturan untuk membenarkan tindakan selanjutnya yang dilakukan dari jenis yang sama. Metode preseden ini dipilih karena merupakan salah satu cara dalam pembelajaran yang sangat efektif dengan menganalisis sebuah contoh bangunan proyek. Dengan menganalisis, kita akan mendapatkan informasi yang dibutuhkan untuk merancang desain proyek serupa.

Metode preseden yang dipilih adalah metode preseden Roger Clark dalam Precedents in Architecture: Analytic Diagrams, Formative Ideas, and Partis (1985). Metode ini memberikan sebelas pedoman untuk dilakukan dalam menganalisis contoh proyek bangunan arsitektur:

\section{a. Struktur (Structure)}


Struktur yang menjadi sebuah kekokohan dan kekuatan dalam suatu bangunan. Pada tingkat yang lebih tinggi, struktur bangunan dapat dikembangkan oleh arsitek menjadi konsep bangunan dan keindahan.

b. Cahaya alami (Natural Light)

Cahaya matahari yang masuk ke dalam bangunan memiliki fungsi untuk memberikan suasana dan kualitas ruang. Cahaya ini dapat memberikan persepsi ruang yang berbeda bagi orang yang ada di dalam.

c. Massa Bangunan (Building Mass)

Massa bangunan adalah nilai bentuk sebuah bangunan seluruhnya, bukan hanya siluet atau permainan tebal dan tinggi massa. Massa ini adalah tiga dimensi hasil dari rancangan seorang arsitek.

d. Denah ke Potongan atau Tampak (Plan to Section or Elevation)

Denah, Tampak, dan Potongan merupakan gambar dasar yang umum untuk perancangan horizontal dan vertikal pada tiga dimensi bangunan. Denah dapat menjadi alat utama untuk mengatur kegiatan dan sebagai rancangan awal bentuk bangunan arsitektur.

e. Sirkulasi Untuk Menggunakan Ruang (Circulation to Use Space)

Sirkulasi dan penggunaan ruang adalah poin dalam komponen statis dan dinamis di semua bangunan. Penggunaan ruang adalah fokus utama seorang arsitek untuk efektivitas fungsi ruang. Sirkulasi akan membentuk dan menentukan bagaimana suasana dan pengalaman ruang, memberikan pemahaman konfigurasi ruang secara keseluruhan.

f. Unit ke Seluruh (Unit to Whole)

Hubungan unit dengan keseluruhan untuk menguji arsitektur sebagai unit yang dapat dihubungkan untuk membuat bangunan. Unit adalah sesuatu yang unik dan nyata yang diidentifikasikan sebagai bagian dari bangunan.

g. Repetisi ke Unik (Repetitive to Unique)

Hubungan berulang dengan elemen unik mensyaratkan eksplorasi komponen spasial dan formal untuk atribut yang membuat komponen ini sebagai suatu yang unik dan nyata.

h. Simetri dan Keseimbangan (Symmetry and Balance)

Konsep keseimbangan dan simetri telah menjadi dasar arsitektural. Keseimbangani ini terjadi melalui penggunaan komponen komposisi yang mengartikan hubungan paralel setiap aksen. Seperti unit ' $A$ ' jumlahnya sama dengan unit ' $B$ ' dan sisanya adalah hubungan antara kedua unit.

i. Geometri (Geometry)

Bentuk dasar diartikan sebagai pengembangan dari pengulangan bentuk dasar. Geometri adalah penentu tunggal atau karakteristik paling umum dan dalam bangunan. Dapat digunakan pada berbagai bentuk variasi, sistem proporsi ruang dan bentuk gabungan kompleks yang dihasilkan untuk massa.

j. Penambahan dan Pengurangan (Additive and Subtractive)

Ide penambahan dan pengurangan adalah teknik untuk mencapai bentukan yang ideal karena perlunya untuk mencapai konsep proyek bangunan oleh seorang arsitek.

k. Hirarki (Hierarchy)

Hirarki mengartikan perubahan urutan tingkat dari satu keadaan ke keadaan lain dimana rentang seperti terbuka-tertutup, sederhana-kompleks, publik-privat, dan minimaliskompleks. Dalam menganalisis hirarki ini mendominasi kepentingan bentuk ruang melalui keseluruhan unsur yang ada pada ruang.

\section{DISKUSI DAN HASIL}

\section{Tinjauan Tapak}

Tapak terpilih merupakan Perempatan Cengkareng yang sangat padat dengan berbagai moda transportasi. Tapak berada di Jl. Lingkar Luar Barat, Kelurahan Rawa Buaya, Kecamatan Cengkareng, Jakarta Barat. Kondisi eksisting berupa tanah kosong yang ada beberapa vegetasi 
serta sebagian rumah slum warga. Tapak diapit oleh area pemukiman penduduk dan pusat pembelanjaan. Tapak dapat diakses dengan mudah melalui jalan primer, yaitu Jalan Raya Lingkar Luar Barat dan Jalan Raya Daan Mogot. Berikut adalah data tapak yang dipilih:

- Zona: mixed use

- Luas: $9500 \mathrm{~m}$

- KDB: $40 \%$

- KLB: 1.6

- KB: 4

- $\quad$ KTB 55

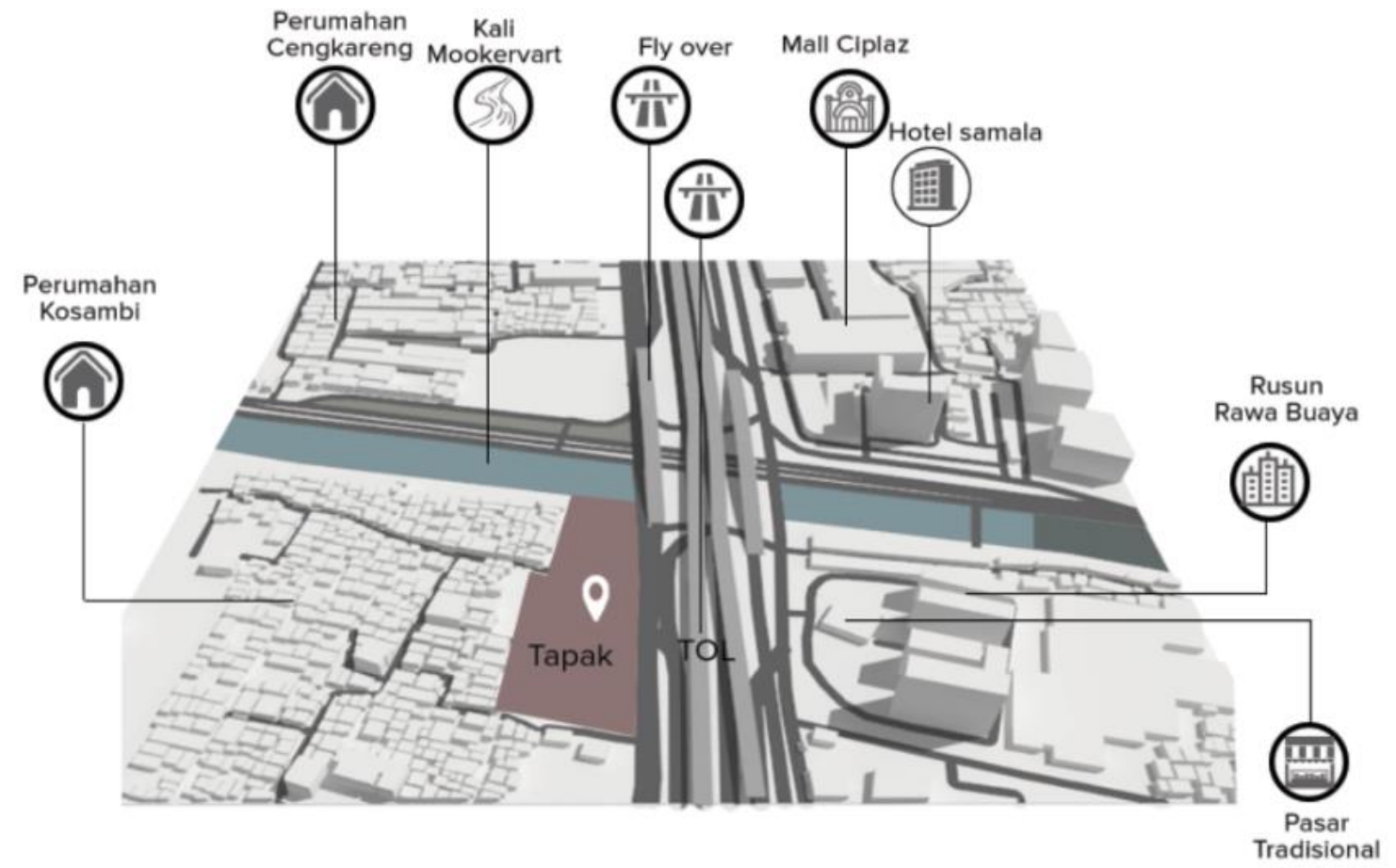

Gambar 1. Sekitar tapak

Sumber : Data Pribadi, 2021

\section{SWOT}

- Strenght: Tapak berada di area ramai permukiman warga dengan akses yang mudah. Lokasi tapak berada di dekat area perencanaan pembangunan MRT dan LRT fase 3 Jakarta.

- Weakness: Tapak berada di titik rawan kemacetan saat jam sibuk. Orientasi tapak lebih mengarah ke arah timur.

- Opportunity: Pembangunan proyek ini dapat menyelesaikan masalah kemacetan yang berasal dari kendaraan umum yang berhenti sembarangan dan pedagang kaki lima lima yang tidak tertata rapih.

- Threat: Akses masuk ke tapak hanya mengandalkan satu jalur jalan, terdapat perempatan besar di depan tapak yang dapat menimbulkan kemacetan di depan tapak.

\section{Penerapan Konsep ke Dalam Proyek}

Dalam merancang pusat transportasi ini, yang menjadi poin yang paling diutamakan adalah sirkulasi kendaraan dan sirkulasi pedestrian sehingga peletakkan masa dibuat dengan menciptakan plaza untuk akses. Untuk menciptakan bangunan yang tanggap dengan konsep 
beyond ecology maka dibuat parameter konsep dengan menciptakan bangunan dengan arsitektur yang modern dan ramah lingkungan.

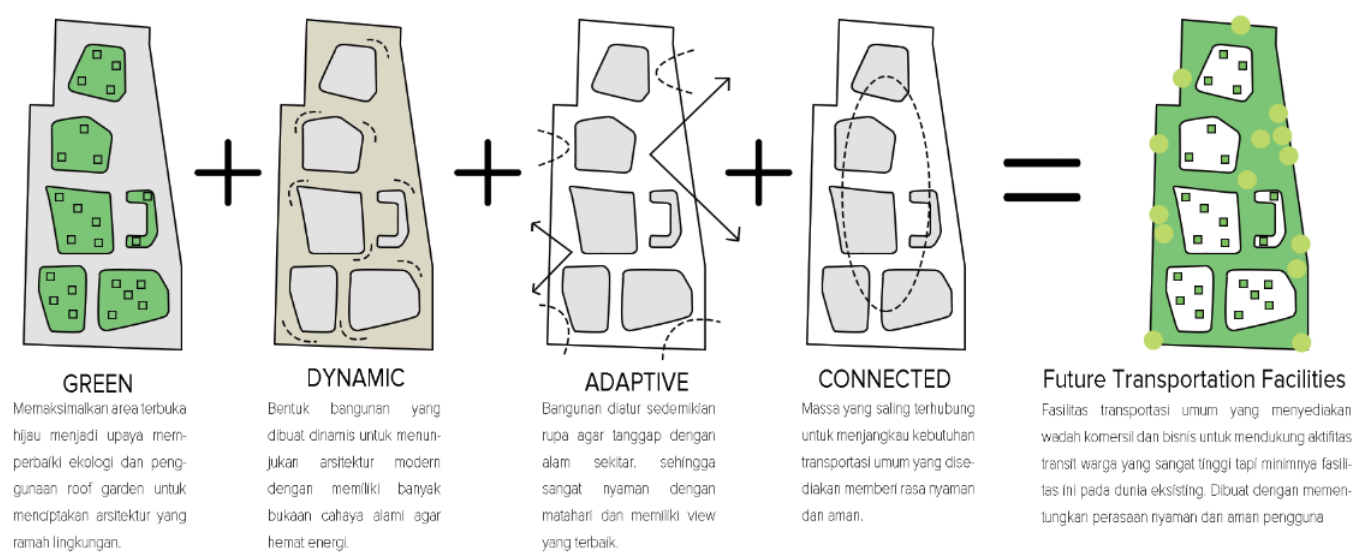

Gambar 2. Konsep

Sumber : Data Pribadi, 2021

Dengan menciptakan Future transportation facilities maka proyek akan menjadi pusat transportasi bagi masyarakat yang sangat mengedepankan aman dan nyaman. Pembagian fungsi massa untuk setiap moda transportasi yang dilengkapi dengan retail, sedangkan untuk bentuk massa menghasilakn bentuk memberi kesan arsitektur modern dan arsitektur hijau. Desain ini memanfaatkan semaksimal mungkin ruang terbuka hijau agar terjaga dan dapat dimanfaatkan untuk mengurangi polusi yang diakibatkan oleh proyek ini.

\section{Program}

Terdapat tiga program yang berkaitan untuk mewujudkan pusat transportasi ini. Program utama merupakan stasiun MRT, program kedua merupakan pusat transit halte transportasi umum, yang ketiga adalah retail dan ruang komunal sebagai pendukung.

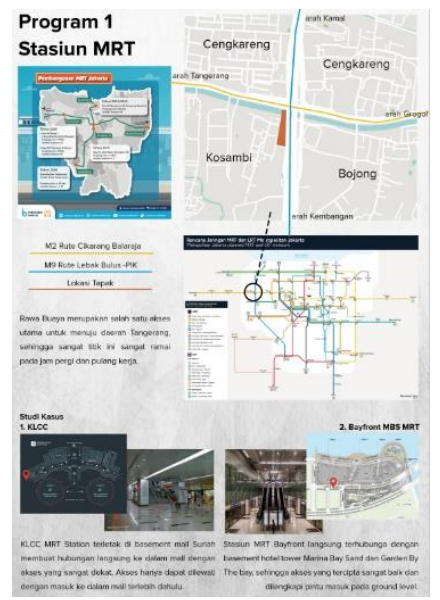

Gambar 3. Program 1 Sumber : Data Pribadi

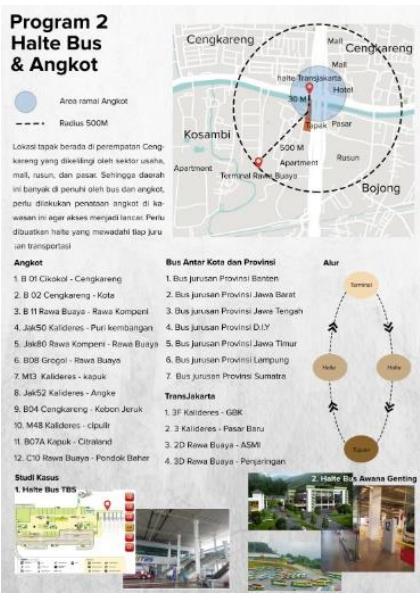

Gambar 4. Program Sumber : Data Pribadi

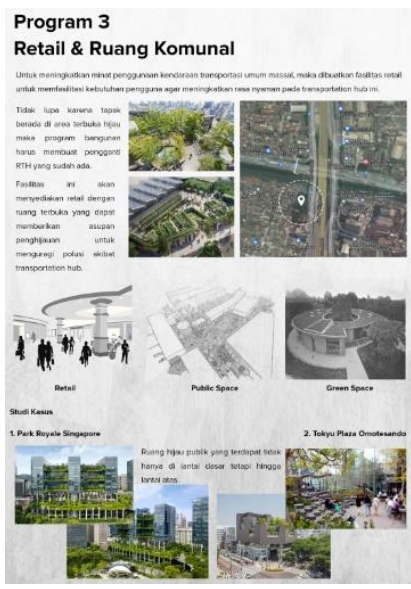

Gambar 5. Program 3 Sumber : Data Pribadi

Setiap program memiliki keterkaitan dengan program lainnya untuk memberikan kenyaman bagi pengguna fasilitas. Program ini semua terhubung sehingga pengguna dapat transit ke antar moda transportasi dengan mudah dan nyaman. 


\section{Strategi Desain}

Seluruh massa bangunan akan dibuat dengan menggunakan roof garden agar menciptakan tambahan ruang terbuka hijau bagi bangunan menunjukkan arsitektur hijau dan dapat dimanfaatkan menjadi ruang untuk bersantai. Selain dari itu ruang terbuka hijau pada tapak juga diolah menjadikan penghubung setiap massa dan menciptakan kesan fasiltias transportasi yang nyaman. Pusat transportasi ini akan mengusung konsep baru untuk dijadikan landmark, maka façade dibuat semenarik mungkin dengan sistem kaca curtain yang dapat menarik pandangan orang ke dalam tapak. Berdasarkan studi preseden yang diambil, pusat transportasi yang dibuat menjadi landmark akan menarik pengguna. Ditambah dengan suasana pusat transportasi yang nyaman dapat semakin mendorong jumlah pengguna transportasi umum.
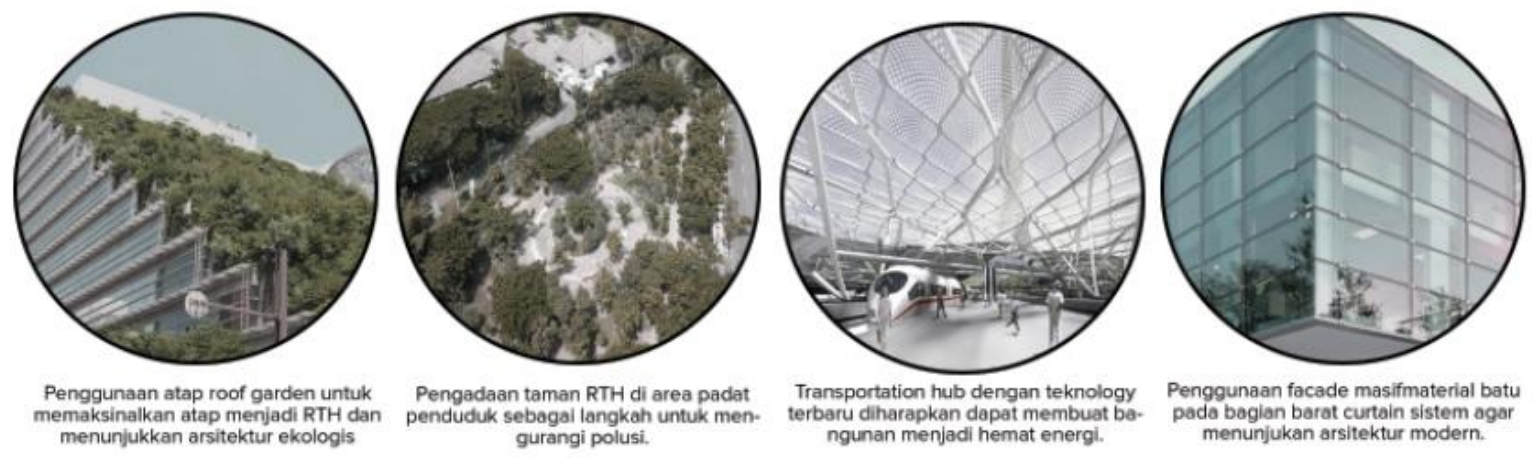

Gambar 6. Strategi Desain

Sumber : Data Pribadi, 2021

Selain itu, massa bangunan akan dibuat multi massa agar tercipta lorong yang dapat dimanfaatkan menjadi plaza dan dapat memasukan elemen alam seperti sinar matahari dan angin ke dalam tapak. Untuk mengurangi sinar matahari yang langsung menusuk ke dalam bangunan maka akan digunakan second skin untuk menguranginya, serta memberikan bentuk ke façade yang lebih arsitektural. Dengan konsep ini, akan tercipta fasilitas transportasi yang sangat baru khususnya di kota Jakarta. Massa ini akan terkoneksi dengan area sekitar sehingga dapat diakses dengan mudah oleh masyarakat di Kelurahan Rawa Buaya dan sekitarnya. Dari studi preseden, dapat dipelajari bahwa poin penting dalam perancangan pusat transportasi itu adalah sirkulasi, sehingga sirkulasi dibuat bercabang untuk menghindari titik-titik keramaian dan crossing. Pada pembangunan fasilitas umum sekarang, pada studi preseden sangat lekat dengan arsitektur ramah lingkungan, sehingga desain pusat transportasi ini harus meminimalisir polusi dan hemat energi.

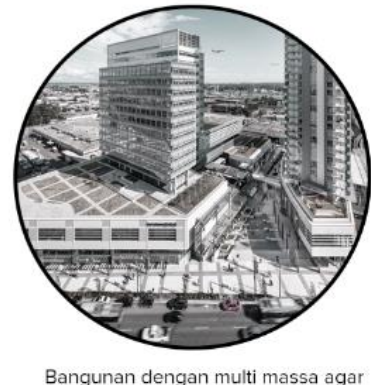

Bangunan dengan multi massa agar
menciptakan plaza untuk ruang komunal bersama

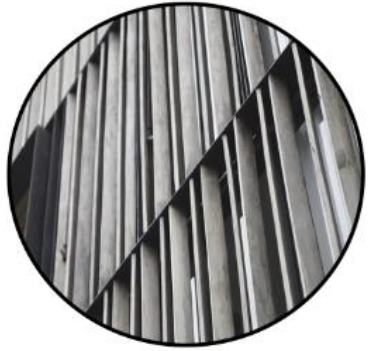

Penggunaan second skin untuk menimalisir cahaya alami yang masuk da memberikan bentuk facade.

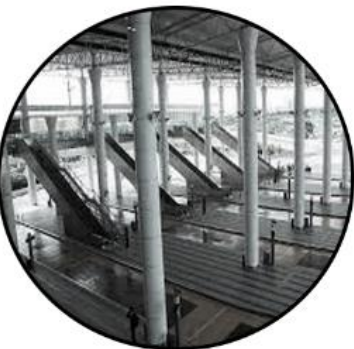

Menghadirkan suasana baru dan lebih nyaman untuk setiap halte dan peron nya.

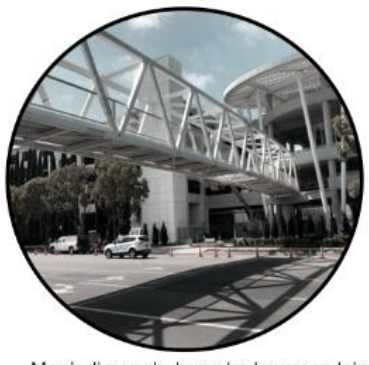

Menjadi penghubung ke kawasan lain untuk bidang transportasi sehingga dibterdekat.

Gambar 7. Strategi Desain

Sumber : Data Pribadi, 2021 
Ruang publik yang tercipta diantara massa akan diolah menjadi plaza dengan landscape yang nyaman dan dapat menghubungkan setiap fungsi moda transportasi, karena saat jam sibuk, plaza ini akan terisi oleh banyak pengguna daripada yang menunggu di salah satu moda transportasi. Bagian sisi bangunan akan dibuat dengan menonjolkan struktur dengan penggunaan kaca curtain, yang berfungsi untuk memaksimalkan view dari massa bangunan ke arah dalam tapak atau plaza. Atap skylight akan digunakan pada tengah massa untuk memberikan sinar masuk ke dalam bangunan menjadikan bangunan ini hemat energi, sekaligus untuk entrance ke roof top.

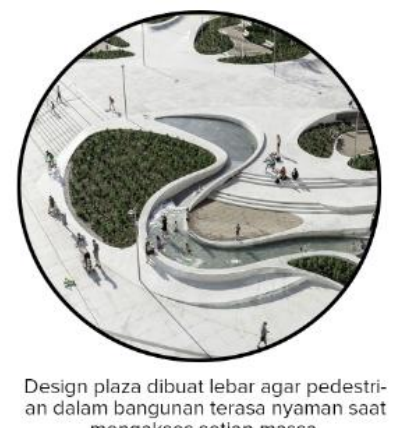
mengakses setiap massa

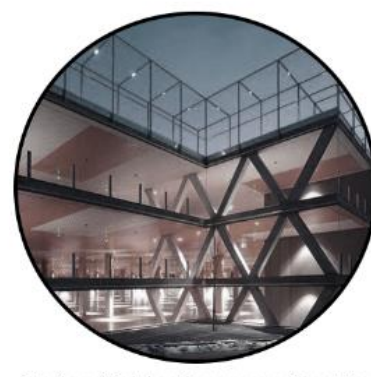

Bagian sisi dalam bangunan dibuat terbuka dengan menonjolkan struktur tapak.
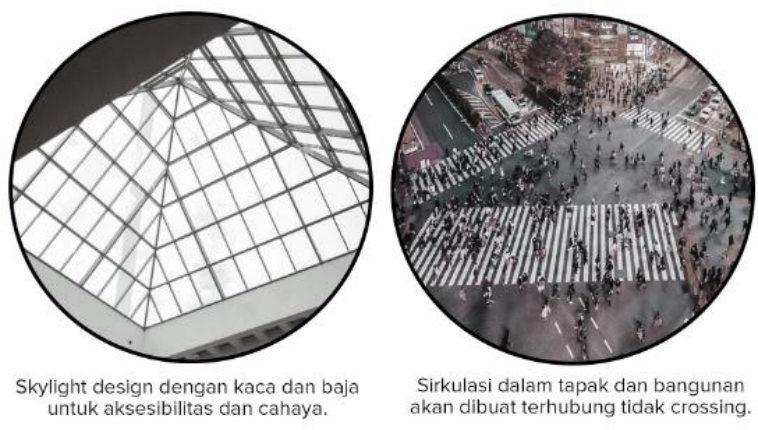

Sirkulasi dalam tapak dan bangunan akan dibuat terhubung tidak crossing.

Dengan panduan dari studi preseden, strategi desain ini mengutamakan dalam perancangan sirkulasi dan lingkungan. Sirkulasi yang tidak saling menyilang dan panduan yang jelas pada setiap bangunan moda transportasi akan membuat petunjuk yang mudah bagi para pengguna dan tidak membingungkan. Landscape yang diolah yang baik akan menciptakan kenyamanan bagi pengguna. Fungsi program akan membantu kawasan ini menjadi kawasan transit oriented development (TOD).

\section{Proses Gubah Massa}

Gubah massa didapatkan dari bentuk tapak yang sudah ditandai dahulu dengan peletakan sirkulasi bagi pengguna dan kendaraan. Lalu massa dibuat dengan konsep form follow function sehingga jadi lebih sederhana. Massa yang sederhana ini dibentuk menjadi dinamis dengan melengkungkan bentuk bangunan agar tercipta kesan arsitektur modern. Lalu diolah lebih dalam dengan façade dan landscape-nya agar tercipta sebuah bangunan pusat transportasi yang tanggap alam dan modern. 


\section{PROSES GUBAH MASSA}
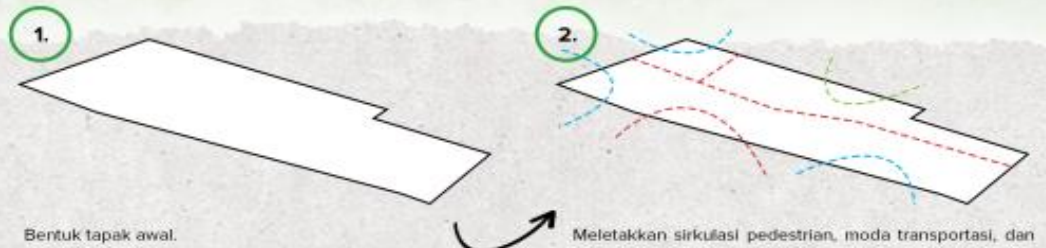

service dalsm tapak yang merupakan unsur tempenting.
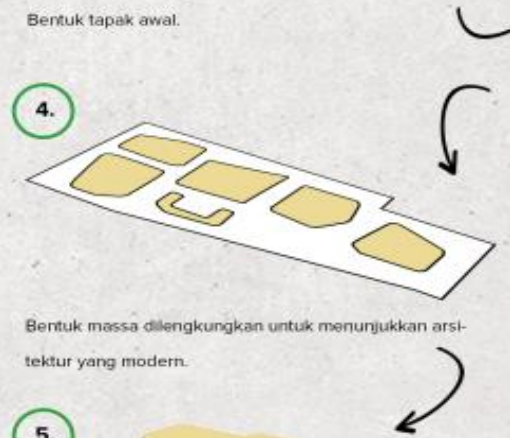

(3.)

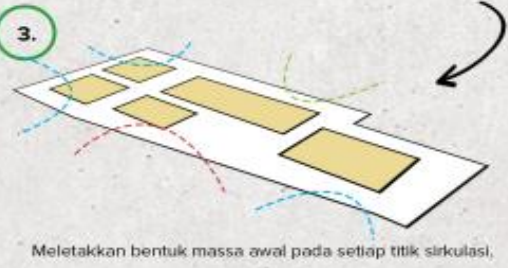

Massa ini dibuat dengan multi massa untuk sirkulasi dan menjadi bangunan yang memantaatkan udara dan sinar
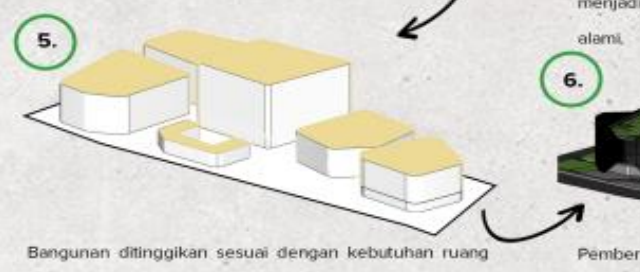

pada program dan KLB dengan konsep form follow func-

Pemberian second skin, root garden, Jan pengolahan tion.

pada plaza untuk menciptakan transportation hub yang
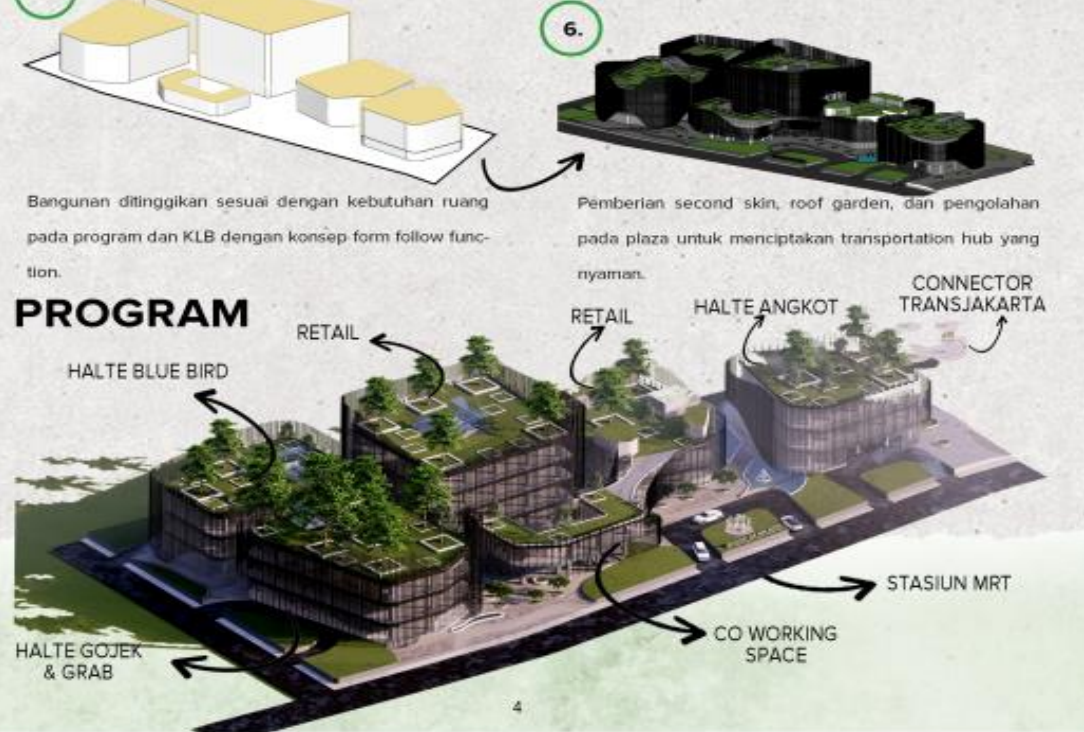

Gambar 8. Proses Gubah massa

Sumber : Data Pribadi, 2021

\section{Parameter Beyond Ecology}

- Energy and Emission : Penggunaan material atap roof garden dan pemanfaatan ruang terbuka hijau yang maksimal menciptakan arsitektur ekologis yang dapat mengurangi polusi udara

- Adaptation : Proyek ini dapat menjadi pendorong bagi masyarakat sekitar Rawa Buaya untuk memilih kendaraan umum daripada kendaraan pribadi sehingga menghasilkan budaya baru bagi masyarakat.

- New Technology: Pusat transportasi baru bagi masyarakat di area pinggir kota yang dapat dimanfaatkan untuk fasilitas umum yang dapat memenuhi kebutuhan penduduk untuk beraktifitas ke pusat kota.

- Sustainable Digital : keberlanjutan adalah konsep utama perancangan agar dapat lebih menghemat energi dan minim limbah yang dihasilkan oleh penggunaan proyek ini. 


\section{Sequences Experience}

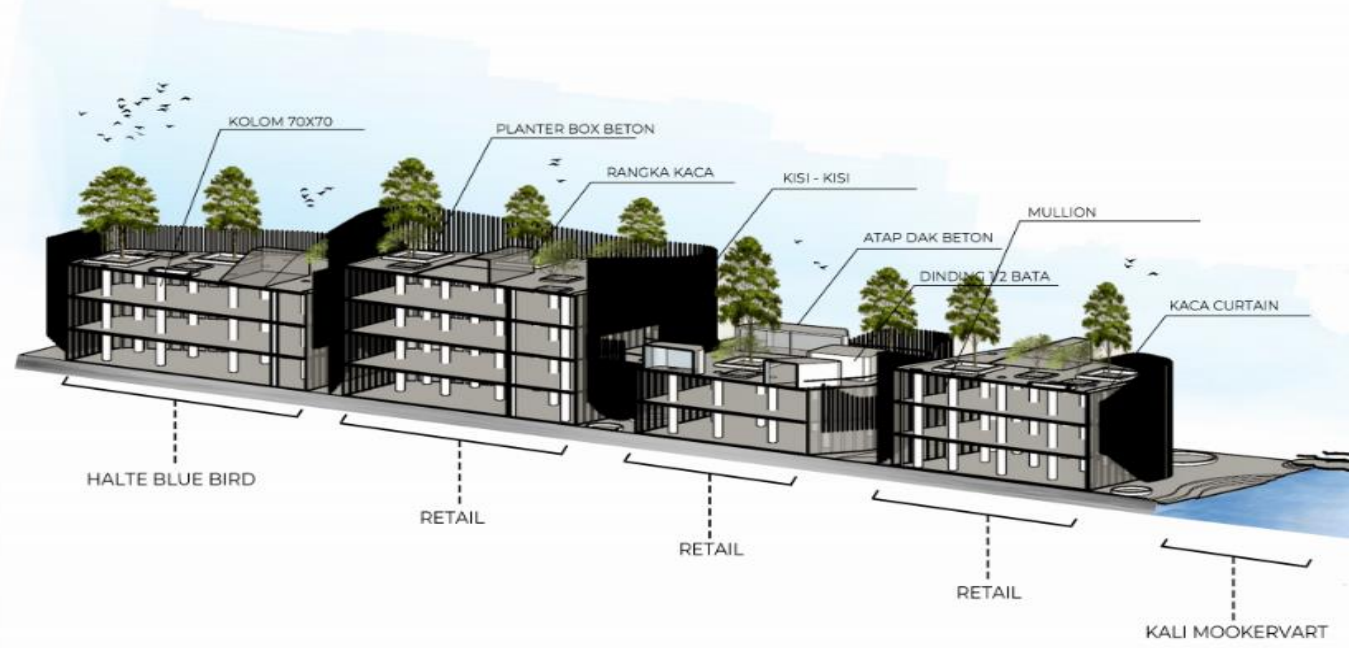

Gambar 9. Potongan 3D

Sumber : Data Pribadi, 2021

Pengalaman ruang yang tercipta akan membuat pengunjung merasa nyaman dengan fasilitas transportasi yang megah dan dipadukan dengan alam. Sirkulasi yang sangat baik membuat jalan yang terpisah dari titik-titik keramaian karena moda transportasi yang terpisah massanya. Cara ini dapat membuat evakuasi menjadi mudah karena memiliki banyak titik kumpul dan banyak akses untuk melarikan diri bila terjadi bencana.

\section{KESIMPULAN DAN SARAN}

\section{Kesimpulan}

Arsitektur dapat mewadahi kebutuhan transportasi umum dengan desain pusat transportasi yang ramah dengan masyarakat dan kawasan itu sendiri. Desain ini seperti membantu menghubungkan kebutuhan-kebutuhan moda transportasi di kawasan ini, serta menyediakan kebutuhan fasilitas yang diperlukan untuk memberikan kesan nyaman dan aman. Metode desain 'Preseden' sudah paling tepat dalam merancang proyek transportasi umum ini, karena proyek ini mengandalkan pengalaman manusia dalam beraktifitas di dalam bangunan fasilitas umum ini. Sehingga mencontoh bangunan di luar negeri yang sudah lebih maju dapat membuat fasilitas umum kita menjadi lebih baik lagi. Terlebih proyek ini dapat mengikut sertakan masyarakat yang ingin bekerja dalam hal bisnis, memberikan lapangan pekerjaan, dan dapat memfasilitasi kendaraan umum kecil seperti taksi online, taksi komersil, ojek online, dan angkot. Program yang dihadirkan dalam proyek ini berupa retail, ruang komunal, dan pusat transportasi umum dapat membantu dalam permasalahan ini. Kedepannya kehidupan Kota Jakarta dapat perlahan berubah bila transporatasi umum massal dijadikan pilihan utama dalam bermobilitas. Membuat kota ini mengalami penurunan polusi udara akibat kemacetan yang ada.

\section{Saran}

Saran untuk pengembangan studi dan desain yaitu:

a. Bagi masyarakat di kawasan Rawa Buaya dan sekitarnya dapa menggunakan proyek ini sebagai tempat pusat transportasi bersama yang sangat nyaman dan aman untuk meningkatkan kemauan masyarakat untuk menggunakan transportasi umum.

b. Studi untuk pengembangan metode Transit Oriented Development dapat terus dikembangaknan agar dapat terealisasikan di Kota Jakarta, yang dapat membuat menurunnya penggunaan kendaraan pribadi di dalam kota. 


\section{REFERENSI}

Bishop, Z. (2015). Transit-Oriented Development: Benefits and Studies. Virginia: Ball State University

Calthorpe Associates. (1993). Transit Oriented Development Design Concepts. San Jose: Transportation Agency

Clark. R. H. (1985). Precedents in Architecture: Analytic Diagrams, Formative Ideas, and Partis. New Jersey: John Wiley and Sons.

ITDP (Institute for Transportation Development Policy). 2015. TOD Standard. Despachio: New York

Perda Prov DKI no. 1 Tahun 2012 Rencana Tata Ruang Wilayah (RTRW) Kota Jakarta 20102030

Badan Pusat Statistik Provinsi DKI Jakarta. (2019)

Lynch, K, (1992), The Image of The City. London: The MIT Press

Neufert, E. (1996). Data Arsitek. Jilid 1. Terjemahan. Penerbit Erlangga: Jakarta.

Neufert, E. (2002). Data Arsitek. Jilid 2. Terjemahan. Penerbit Erlangga: Jakarta

Direktorat Jenderal Perhubungan Darat (1998). Satuan Ruang Parkir.

Srihadi, E. (2010). "Problem Kemacetan Jakarta" 2010. Update Indonesia, Volume V No. 5: 2-3 Jumlah Penduduk dan Rasio Jenis Kelamin Menurut Kabupaten Kota di Provinsi DKI Jakarta.https://jakarta.bps.go.id/statictable/2017/01/24/91/3-1-2-jumlahpendudukdan-rasiojenis-kelamin-menurut-kabupaten-kota-di-provinsi-dkijakarta2015.html. 2021.

https://www.archdaily.com/804628/marine-gateway-perkins-plus-

will?ad_source=search\&ad_medium=search_result_all

https://www.archdaily.com/588218/rotterdam-central-station-benthem-crouwel-architectsmvsa-meyer-en-van-schooten-architecten-and-west8 ?ad_source=search\&ad_medium=search_result_all

https://www.archdaily.com/940694/elevated-stations-of-guangzhou-metro-line-21gdad?ad_source=search\&ad_medium=search_result_all

https://www.archdaily.com/931888/cuatro-caminos-transit-oriented-development-manuelcervantes-cespedes-plus jsa?ad_source=search\&ad_medium=search_result_all

https://www.nap.edu/read/23360/chapter/6 2021

http://johannes.lecture.ub.ac.id/files/2012/10/Tata-Cara-Perencanaan-LingkunganPerumahan-di-Perkotaan-_-SNI-03-1733-2004.pdf

https://peraturan.bpk.go.id/Home/Details/103801/permen-agrariakepala-bpn-no-16-tahun2017

https://news.detik.com/berita/d-3407286/terminal-terintegrasi-Irt-dan-mrt-akan-dibangun-dirawa-buaya

https://www.liputan6.com/news/read/2844036/mengintip-rencana-pemprov-dki-relokasiterminal-kalideres

https://wartakota.tribunnews.com/2020/06/03/jalan-daan-mogot-kembali-macet-jelang-h-1psbb-fase-3-berakhir

http://www.planhillsborough.org/plan-hillsborough-city-of-tampa-hart-land-fta-tod-grant/ https://statistik.jakarta.go.id/transportasi-dki-jakarta-2017/

https://statistik.jakarta.go.id/peningkatan-jumlah-kendaraan-bermotor-di-dki-jakarta/ https://perkim.id/transportasi/penerapan-konsep-transit-oriented-development-tod-padapenataan-kota/ 